\title{
Selamento de lesões de cárie oclusais em molares decíduos: relato de dois casos clínicos
}

\author{
Sealing of occlusal cavity injuries on deciduous molars: \\ a report of two cases
}

\author{
Yohana de Oliveira Ponte* \\ Amanda de Albuquerque Vasconcelos ${ }^{* *}$ \\ Daniela Cavalcante Girão ${ }^{* * *}$ \\ Italo Sarto Carvalho Rodrigues**** \\ José Carlos Pettorossi Imparato****
}

\section{Resumo}

Objetivo: relatar dois casos clínicos sobre selamento de lesões de cárie em dentina com resina flow em molares decíduos. Relato de caso: foram selecionadas duas crianças, de 4 e 6 anos de idade, que apresentavam lesão de cárie oclusal, com abertura menor do que três milímetros e profundidade envolvendo a dentina: uma localizava-se na metade externa, e outra, iniciando a progressão para metade interna. $O$ selamento das lesões foi realizado com resina flow (Natural Flow - DFL), depois de prévio condicionamento com ácido fosfórico a $37 \%$ e aplicação do sistema adesivo na cavidade. Foi realizado acompanhamento clínico e radiográfico de seis meses, analisando a integridade do material de selamento e a progressão das lesões de cárie. Nos dois casos, houve retenção completa do material selador, que se manteve íntegro. Radiograficamente, as lesões de cárie não apresentaram progressão, pelo contrário, houve sinais de regressão, aumentando as chances de um bom prognóstico. Considerações finais: o selamento de lesões de cárie com resina flow, desde que devidamente controlado clínica e radiograficamente, pode propiciar a paralisação de lesões de cárie em dentina, sendo uma abordagem altamente vantajosa, não invasiva, de baixo custo e que preserva os tecidos dentais.

Palavras-chave: Dente decíduo. Dentística operatória. Cárie dentária. Odontopediatria. Selantes de fossas e fissuras.

\section{Introdução}

O processo de cárie dentária caracteriza-se por ser uma condição patológica que acomete os componentes minerais dos dentes, sendo entendida como um processo dinâmico que se desenvolve a partir de estágios submicroscópicos até sinais e sintomas clínicos de fácil detecção ${ }^{1}$. Durante muito tempo, a terapêutica predominante restringia-se ao tratamento por meio da remoção do tecido cariado ${ }^{2}$, porém, estudos sugerem que não é necessário a remoção de tecido infectado com o intuito de paralisar o processo cariogênico ${ }^{3-8}$.

A partir do advento da mínima intervenção na Odontologia, as lesões diagnosticadas precocemente começaram a receber tratamentos não invasivos envolvendo condutas de paralisação e controle ${ }^{9}$. As abordagens não invasivas são vantajosas em crianças, pois, além de preservarem tecidos dentais saudáveis, são mais rápidas e de baixo custo ${ }^{10-11}$. Os selantes resinosos de fóssulas e fissuras foram desenvolvidos com finalidade preventiva, sendo aplicados sobre a face oclusal de dentes suscetíveis ao desenvolvimento de lesões de cárie, formando uma barreira mecânica que impede a retenção de restos alimentares e a formação de biofilme nas áreas de difícil controle de higiene, prevenindo assim o desenvolvimento da lesão de cárie ${ }^{6,12}$.

***** Doutor, professor do Departamento de Ortodontia e Odontopediatria da Faculdade de Odontologia da Universidade de São Paulo e do Centro de PósGraduação São Leopoldo Mandic, Unidade Fortaleza, Ceará, Brasil. 
O principal critério de sucesso para a ação preventiva dos selantes resinosos é com base na sua taxa de retenção. O uso de resinas compostas fluidas (resina flow) como selantes de fóssulas e fissuras é sugerido para os casos de fissuras alargadas e profundas. Com formulações bastante próximas aos selantes resinosos, apresenta, porém, propriedades físicas e mecânicas melhores ${ }^{13}$. As resinas compostas fluidas têm ganhado popularidade devido à facilidade de aplicação, bem como às evidências científicas que demonstram a ocorrência de menos microinfiltração, pois têm mais carga. Assim, acredita-se que os resultados clínicos sejam similares ${ }^{14}$.

O objetivo do estudo é relatar dois casos clínicos de lesões de cárie oclusais em dentina de molares decíduos seladas com resina flow, avaliando a integridade do selamento e a progressão da lesão de cárie por meio de controles clínico e radiográfico.

\section{Relato de caso clínico}

Foram selecionados dois pacientes normossistêmicos, sendo Paciente J.S.A.S., 6 anos de idade, sexo masculino, com lesão de cárie em face oclusal, em metade externa de dentina, no elemento dentário 54; e Paciente L.R.C., 4 anos de idade, sexo feminino, com lesão de cárie em face oclusal, no elemento dentário 54. Observou-se que a lesão de cárie estava localizada na região intermediária entre metades externa e interna de dentina do molar decíduo, sem acometimento pulpar e sem sintomatologia dolorosa.

Por meio da inspeção visual, observou-se que, nos dois casos clínicos, as lesões apresentavam-se cavitadas e com menos de $3 \mathrm{~mm}$ de abertura em superfície oclusal; essas medidas foram obtidas com auxílio de uma sonda milimetrada do tipo OMS (ball-point) (Figura 1).

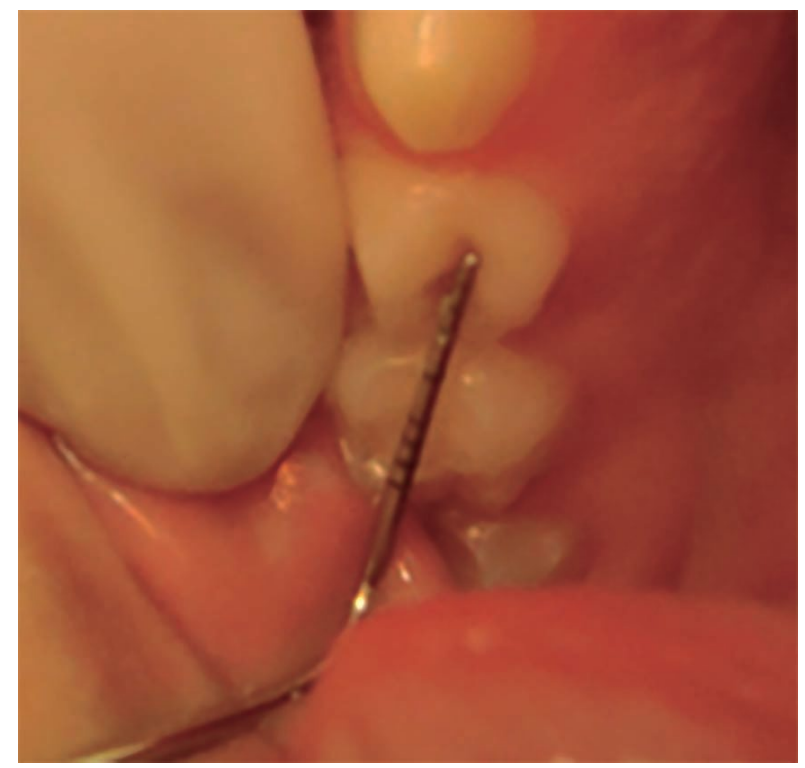

Figura 1 - Cavidade com abertura oclusal igual ou menor que $3 \mathrm{~mm}$ Fonte: acervo pessoal.
Como teste complementar, foi realizado exame radiográfico interproximal convencional (bite-wing) com o auxílio de posicionador radiográfico infantil, para a análise e a confirmação de diagnóstico de lesão de cárie nos elementos dentários, método radiográfico também utilizado no estudo de Borges et al. ${ }^{11}$ (2012) (Figura 2).

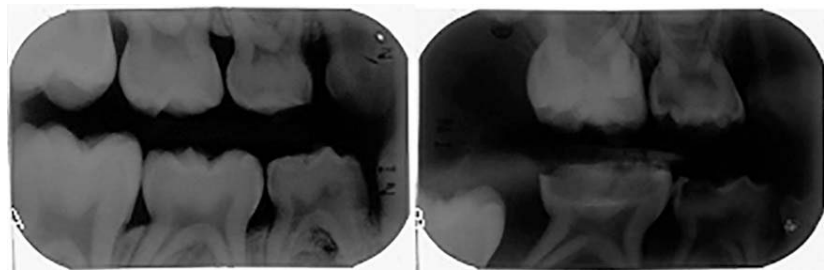

Figura 2 - Aspecto radiográfico inicial

Legenda: A) Rx interproximal do Paciente J.S.A.S., dente 54, lesão com profundidade em metade externa da dentina; B) Rx interproximal da Paciente L.R.C., dente 54, lesão com profundidade na região entre metades externa e interna da dentina.

Fonte: acervo pessoal.

Optou-se por um tratamento conservador, baseado na mínima intervenção, na não remoção do tecido cariado e no vedamento das lesões cariosas, assim como adotado em outros estudos ${ }^{6,8,15}$.

Os pacientes foram submetidos à profilaxia dentária com escova de Robinson em caneta de baixa rotação, pedra-pomes e água. Os selamentos das lesões foram realizados sob isolamento absoluto dos elementos dentários envolvidos, seguindo os passos descritos: condicionamento da cavidade oclusal com ácido fosfórico a 37\% (Condac 37\%, FGM), durante 15 segundos em dentina e 30 segundos em esmalte, lavagem com jato de água pelo mesmo tempo, aplicação de adesivo dentinário (Adper Single Bond 2, 3M ESPE, Saint Paul, EUA), conforme orientado pelo fabricante, e fotopolimerização com fotopolimerizador led sem fio de alta potência, durante 20 segundos (Figuras 3 e 4).

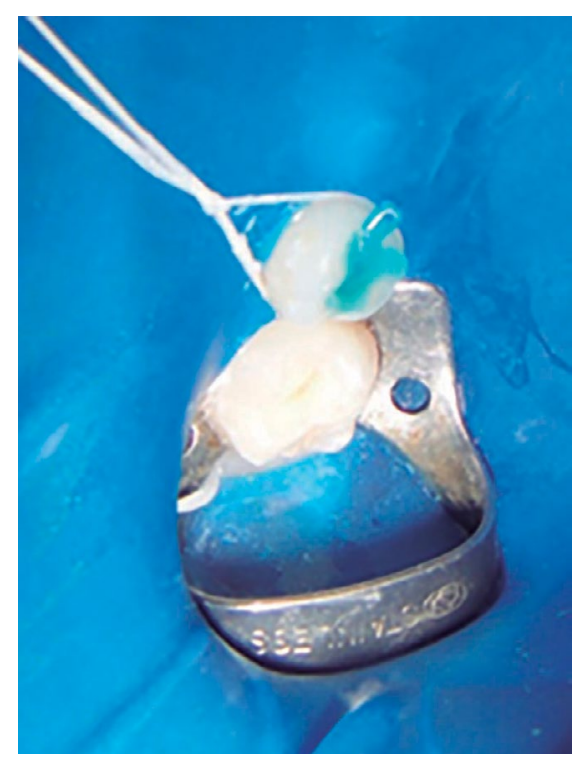

Figura 3 - Aplicação de ácido fosfórico a 37\% Fonte: acervo pessoal. 


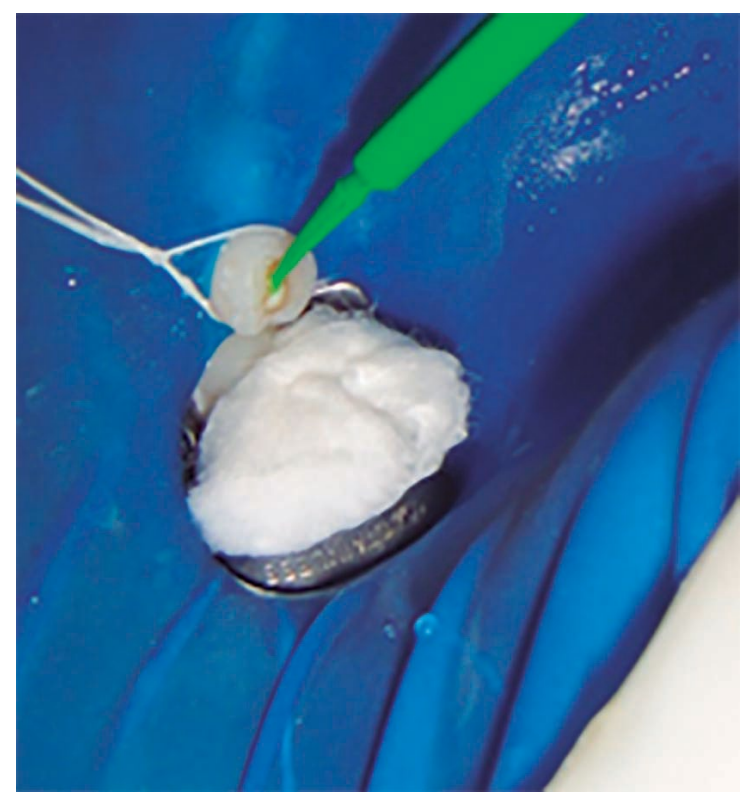

Figura 4 - Aplicação do sistema adesivo

Fonte: acervo pessoal.

Na sequência, realizou-se o selamento da cavidade oclusal com a aplicação de resina flow (Natural Flow - DFL) com o auxílio de uma sonda exploradora. Foram realizados movimentos vibratórios, com o objetivo de aumentar o escoamento do material, minimizando a inclusão de bolhas de ar. O material foi polimerizado durante 20 segundos. A integridade marginal e a retenção do selamento foram verificadas com o auxílio de uma sonda exploradora (Figura 5).

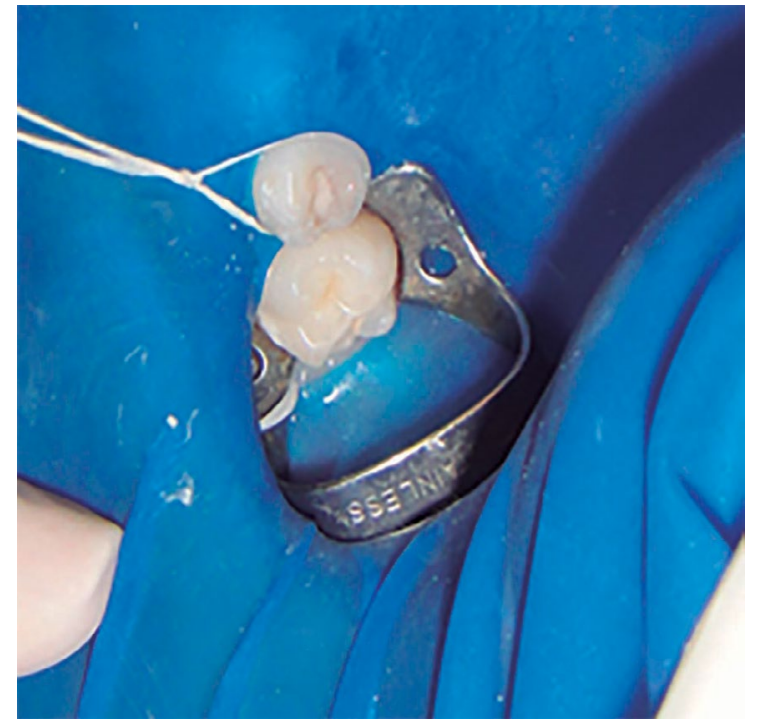

Figura 5 - Aplicação de resina flow

Fonte: acervo pessoal.

Após o término do selamento, foi removido o isolamento absoluto, e, por fim, foi realizado o registro da oclusão com papel carbono. Os ajustes oclusais foram executados com o auxílio de uma broca carbide multilaminada para acabamento de resina composta em alta rotação, sob refrigeração.
Os responsáveis pelas crianças foram orientados com relação a abordagem conservadora utilizada e receberam esclarecimentos quanto à importância de acompanhamentos clínico e radiográfico do elemento dentário com selamento.

Nos dois casos clínicos relatados, os elementos dentários com lesão de cárie oclusal foram examinados clinicamente e radiografados antes e imediatamente após a realização do procedimento clínico (Figura 6).

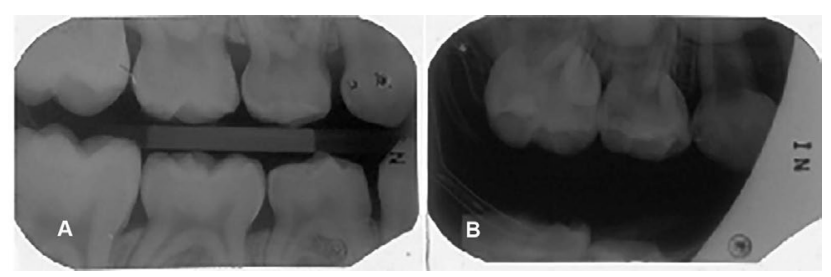

Figura 6 - Aspecto radiográfico imediatamente após o selamento

Legenda: A) Rx interproximal do Paciente J.S.A.S., dente 54; B) Rx interproximal da Paciente L.R.C., dente 54.

Fonte: acervo pessoal.

Após seis meses, entrou-se em contato com os responsáveis pelos pacientes, e foi agendado o retorno para o acompanhamento dos casos. Realizaram-se os exames clínico e radiográfico dos dois elementos dentários selados com resina flow. Verificou-se a presença íntegra do material restaurador na superfície dos elementos dentários, indicando a retenção completa do material, além da paralisação da lesão de cárie, podendo-se observar regressão da lesão de cárie no caso da Paciente L.R.C. (Figura 7).

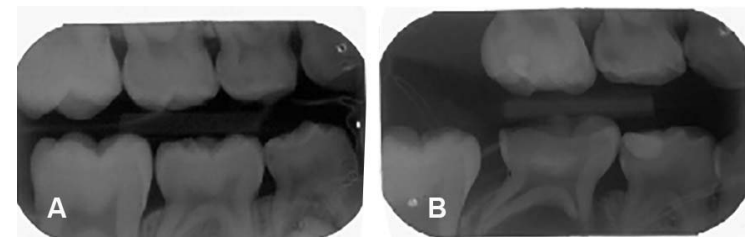

Figura 7 - Acompanhamento radiográfico de lesão de cárie em dentina selada com resina flow sem a remoção prévia da dentina cariada seis meses após o procedimento

Legenda: A) Dente 54 com retenção completa do material e paralisação da lesão de cárie; B) Dente 54 com retenção completa do material e paralisação e regressão da lesão de cárie.

Fonte: acervo pessoal.

Os responsáveis pelas crianças que participaram deste estudo autorizaram a publicação do trabalho por meio da assinatura de um termo de consentimento livre e esclarecido, estando cientes da necessidade de acompanhamentos clínico e radiográfico e da(s) possibilidade(s) de evolução da lesão de cárie e/ou de perda do material selador. Caso acontecesse um destes eventos, durante as consultas de acompanhamento, o tratamento restaurador convencional seria adotado. As duas crianças estavam em acompanhamento odontológico semanal no curso de Odontologia, da Universidade de Fortale$\mathrm{za}$, para as demais questões. 


\section{Discussão}

Foram relatados dois casos clínicos sobre selamento de lesões de cárie oclusais em molares decíduos com resina flow. Com base no acompanhamento destes casos, observou-se o sucesso de uma intervenção minimamente invasiva, sem remoção prévia de tecido cariado e com selamento utilizando resina flow, em que se impediu a progressão da lesão de cárie em cavidades com abertura oclusal de até $3 \mathrm{~mm}$. Ressalta-se a importância de adequados exames clínico e radiográfico para descartar comprometimento pulpar.

Um conceito atual define a cárie dentária como uma doença de progressão contínua, que evolui a partir de uma condição subclínica, passa por alterações na superfície do esmalte e culmina em lesões clinicamente detectáveis ${ }^{16}$

As superfícies oclusais, mesmo com a redução da doença, ainda são responsáveis por $80 \%$ das lesões de cárie ${ }^{17}$, apresentando risco três vezes maior de desenvolvimento de novas lesões, quando comparadas às superfícies lisas ${ }^{18}$.

É consenso na literatura que a superfície oclusal é a face mais susceptível, apontada como a principal responsável pela experiência de lesões de cárie em crianças devido à sua morfologia. Há alta incidência de cárie nessa superfície, relacionando-se à retenção de restos alimentares e à presença de micro-organismos. A possibilidade de obliterar ou vedar essas áreas induziu a idealização dos selantes ${ }^{6,19}$.

Segundo Kramer et al. ${ }^{9}$ (1997), lesões incipientes no esmalte e na dentina passaram a ser tratadas com o intuito de paralisação e controle. Além disso, novas teorias defendem que o biofilme dentário sobre a superfície da lesão é o responsável pelo avanço das lesões cariosas ${ }^{20}$.

Mertz-Fairhurst et al. ${ }^{3}$ (1998) concluíram, após 10 anos de acompanhamento, a não necessidade de remoção de dentina infectada. Logo, o vedamento da cavidade, mesmo sem a remoção do tecido cariado, proporciona a paralisação dessa lesão.

No presente relato, optou-se pelo selamento, mesmo na região intermediária entre metades externa e interna de dentina, visto que as lesões apresentavam-se relativamente distantes da câmara pulpar, sem sintomatologia dolorosa e com pequena abertura oclusal.

Ferreira et al. ${ }^{21}$ (2013) realizaram um estudo em que foram selecionados molares decíduos de crianças entre 5 e 8 anos de idade com lesões de cárie em metade interna de dentina, sem presença de danos pulpares clínicos ou radiográficos, e optaram pelo selamento com cimento de ionômero de vidro, sem remoção prévia de tecido cariado. Os pacientes foram avaliados, clinica e radiograficamente, após um, três, seis e 12 meses e apresentaram bons resultados, justificando, assim, a conduta clínica adotada no caso, em que a lesão de cárie encontrava- -se com progressão no início da metade interna de dentina.

Ricketts et al. ${ }^{22}$ (2006), em revisão sistemática, mostraram que a remoção ultraconservadora do tecido cariado, sem remoção completa da dentina infectada, incorre em menos chances de lesar a polpa dentária, além de não apresentar diferenças em termos de progressão das lesões de cárie. Dessa forma, não se faz necessário a abertura de lesões, visto que o vedamento da cavidade é controlado clinicamente com retornos periódicos, e a progressão da lesão, com controle radiográfico periódico.

Nos casos relatados, foi realizado o condicionamento ácido da superfície dental, pois se observa uma queda de aproximadamente $97 \%$ da microbiota viável em fóssulas e fissuras hígidas após a etapa de condicionamento ácido, confirmando o seu efeito bactericida ${ }^{6}$, além de ser um passo necessário para aplicação da resina flow.

O material escolhido para o selamento das lesões de cárie oclusal foi a resina flow, pois, em estudo, Beun et al. ${ }^{13}$ (2012) afirmam que, embora fissuras pequenas possam ser seladas com selantes de fóssulas e fissuras, em fissuras maiores deve-se usar a resina flow devido às melhores propriedades mecânicas apresentadas.

É importante destacar que nos dois casos clínicos houve retenção total do material após 6 meses de acompanhamento, em conformidade com os estudos de Kramer et al. ${ }^{6}$ (2003), Hesse et al. ${ }^{12}$ (2007), Pellegrinetti et al. ${ }^{8}$ (2009), Hesse et al. ${ }^{15}$ (2014) e Vasconcelos et al. ${ }^{23}$ (2017), que apresentaram taxas elevadas de retenção total do material em seus estudos.

No estudo de Vasconcelos et al. ${ }^{23}$ (2017), ocorreu um baixo índice de reaplicação do material no grupo experimental, apenas em 10\%, após 6 meses do procedimento; o resultado satisfatório foi associado às propriedades mecânicas da resina flow. Ocorreram somente perdas parciais de material: nos estudos de Kramer et al. ${ }^{6}$ (2003), $10 \%$ após 24 meses, de Hesse et al. ${ }^{12}$ (2007), $17 \%$ no período de 12 meses; de Hesse et al. ${ }^{15}$ (2014), 35,3\% ao longo de 18 meses. Observou-se que, mesmo com ausência da progressão da lesão, houve um número considerável de retratamentos no grupo em que foram utilizados selantes de fóssulas e fissuras.

Nos casos relatados, foi observado, por meio da análise radiográfica, que, após o selamento, não houve progressão das lesões de cárie. Também foi observado, nos trabalhos de Kramer et al..$^{6}$ (2003), Hesse et al. ${ }^{12}$ (2007), Pellegrinetti et al. ${ }^{8}$ (2009), Hesse et al. ${ }^{15}$ (2014) e Vasconcelos et al..$^{23}$ (2017), que a paralisação das lesões de cárie ocorreu em todos os casos, desde que as faces oclusais dos molares decíduos sejam devidamente seladas e monitoradas periodicamente. Além disso, nenhum paciente apresentou sintomatologia dolorosa.

No estudo de Hesse et al. ${ }^{15}$ (2014), durante o acompanhamento de 18 meses, não houve diferença 
na progressão da lesão de cárie, independentemente de remoção do tecido cariado. A falta de progressão da lesão de cárie observada nos dentes selados pode ser atribuída à vedação da cavidade. Porém, deve-se destacar que o tamanho da amostra do estudo foi limitado.

Assim, torna-se importante ressaltar que a eficácia da vedação da fissura para paralisar a progressão das lesões de cárie é muito dependente da retenção do vedamento a longo prazo. Quando a retenção do material é completa, a progressão da lesão de cárie é controlada pela restrição de nutrientes para o metabolismo bacteriano $0^{24,25}$.

No estudo de Oliveira et al..$^{26}$ (2006), as lesões de cárie foram avaliadas radiograficamente por $18 \mathrm{me}-$ ses e apresentaram ganho mineral no sexto mês de acompanhamento. No presente trabalho, os casos clínicos foram acompanhados e relatados por seis meses, e foi possível visualizar os primeiros sinais de ganho mineral radiograficamente. É importante ressaltar que o acompanhamento contínuo dos casos está sendo realizado, considerando-se sucesso a estabilização das lesões até a esfoliação dos elementos dentários.

No estudo de Vasconcelos et al. ${ }^{23}$ (2017), foi observado um percentual de $50 \%$ de casos de regressão de lesão de cárie. Alves et al. ${ }^{27}$ (2010) afirmam que o procedimento de selamento é menos invasivo, havendo a possibilidade de remineralização da dentina cariada selada. A imagem radiográfica da $\mathrm{Pa}-$ ciente L.R.C. apresentou sinais mais evidentes de regressão da lesão de cárie após 6 meses de acompanhamento. Acredita-se que isso se deve ao fato de a lesão ser mais profunda, ficando mais evidente 0 ganho mineral.

É válido ressaltar que a técnica apresentada deve ser utilizada com cautela e rigorosos acompanhamentos clínico e radiográfico, devido ao conjunto de requisitos necessários para a obtenção de sucesso no selamento de lesões de cárie. Os critérios são: abertura de no máximo $3 \mathrm{~mm}$ em casos de lesões cavitadas, cavidades restritas a face oclusal, profunidade radiográfica da lesão com distância segura da câmara pulpar, ausência de sintomatologia dolorosa e viabilidade de acompanhamentos clínico e radiográfico. Essas indicações foram relatadas em trabalhos similares ${ }^{6,8,15,23}$. Os casos clínicos apresentam indicações dentro dos parâmetros, justificando o seu sucesso nos acompanhamentos clínico e radiográfico de 6 meses. Este trabalho apresenta como limitações os rigorosos critérios de seleção assim como o tempo curto de acompanhamento registrado. Acredita-se que com o monitoramento do selamento a paralização da lesão continua, visto que, mesmo nos casos com falhas do material apresentados na literatura, não houve progressão da lesão ${ }^{15,23}$.

\section{Considerações finais}

A partir da análise dos dois casos clínicos relatados, pode-se considerar que o selamento de lesão de cárie com resina flow, desde que controlado clinica e radiograficamente, pode propiciar a paralisação de lesões de cárie em dentina, com abertura oclusal de até $3 \mathrm{~mm}$, com profundidade radiográfica em metade externa de dentina ou iniciais em metade interna, com distanciamento seguro da polpa e sem sintomatologia dolorosa em molares decíduos. É uma abordagem altamente vantajosa por ser não invasiva, preservar tecidos dentais, apresentar um custo menos elevado e simplicidade da técnica, diminuindo o tempo clínico. Deve-se ressaltar a importância de acompanhamentos clínico e radiográfico contínuos até a esfoliação do elemento dentário.

\section{Abstract}

Objective: report two clinical cases on flow resin sealing of caries lesions in dentin in primary molars. Case report: two children, aged 4 and 6 years old, presenting occlusal caries lesion, with an opening smaller than three millimeters and depth involving dentin, in which one was located in the outer half of dentin and one beginning the progression to inner half of dentin. The sealing of the lesions was performed with flow resin (Natural Flow - DFL), after previous conditioning with phosphoric acid $37 \%$ and application of the adhesive system in the cavity. A clinical and radiographic follow-up of six months was performed, analyzing the integrity of the sealing material and the progression of caries lesions. In both cases, the complete retention of the sealant material was presented, which remained intact. Radiographically, caries lesions showed no progression, on the contrary, they presented signs of regression in both cases, increasing the chances of a good prognosis. Final considerations: the sealing of caries lesions with flow resin, provided that it is properly controlled clinically and radiographically, leads to the paralysis of caries lesions in dentin, being a highly advantageous, noninvasive, low cost approach that preserves dental tissues.

Keywords: Dental cavity. Operative dentistry. Pediatric dentistry. Pit and fissure sealants. Tooth decay.

\section{Referências}

1. Abuchaim C, Loguercio AD, Grande RHM, Reis A. Abordagem científica clínica do selamento de lesões de cárie em superfícies oclusais e proximais. Rev Gaucha Odontol 2011; 59(1):117-23.

2. Lenzi TL, Guglielmi CAB, Hesse D, Camargo LB, Raggio DP. Dentística Contemporânea: abordagem das superfícies oclusais. In: Imparato, JCP. Anuário odontopediatria clínica: integrada e atual. Nova Odessa: Napoleão; 2013. p. 118-33.

3. Mertz-Fairhurst EJ, Curtis JW Jr, Ergle JW, Rueggeberg FA, Adair SM. Ultraconservative and cariostatic sealed restorations: results at year 10. J Am Dent Assoc 1998; 129(1):55-66. 
4. Maltz M, Carvalho J. Diagnóstico da doença cárie. In: Kriger L, editor. Promoção de saúde bucal. São Paulo: Artes Médicas; 1999. p. 69-91.

5. Massara ML, Alves JB, Brandao PR. Atraumatic restorative treatment: clinical, ultrastructural and chemical analysis. Caries Res 2002; 36(6):430-6.

6. Kramer PF, Cardoso L, Reis ASP, Silveira D, Tovo MF. Efeito da aplicação de selantes de fossas e fissuras na progressão de lesões cariosas oclusais em molares decíduos: observações clínicas e radiográficas. Rev Ibero Am Odotopediatr Odontol Bebê 2003; 6(34):504-14.

7. Hesse D, Bonifácio CC, Raggio DP, Mendes FM, Imparato JCP. Avaliações clínica e radiográfica do selamento de lesões de cárie. Rev Perio News 2008; 2(2):137-43.

8. Pellegrinetti MB, Imparato JCP, Raggio DP, Politano GT, Guedes-Pinto AC. Avaliação do selamento de lesões de cárie em dentina de dentes decíduos. Rev Assoc Paul Cir Dent 2009; 63(1):20-6

9. Kramer PF, Feldens CA, Romano AR. Promoção de saúde bucal em odontopediatria. São Paulo: Artes Médicas; 1997.

10. Mickenautsch S, Frencken JE, Van't Hof M. Atraumatic restorative treatment and dental anxiety in outpatients attending public oral health clinics in South Africa. J Public Health Dent 2007; 67(3):179-84.

11. Borges BC, Araújo RF, Dantas RF, Lucena AA, Pinheiro IV. Efficacy of a non-drilling approach to manage non-cavitated dentin occlusal caries in primary molars: a 12-month randomized controlled clinical trial. Int J Paediatr Dent 2012; 22(1):44-51.

12. Hesse D, Bonifácio CC, Raggio DP, Imparato JCP. Avaliação do selamento de lesões de cárie comparado à restauração com resina composta em dentes decíduos. Stomatos (Ulbra) 2007; 13(1):75-85.

13. Beun S, Bailly C, Devauz J, Leloup G. Physical, mechanical and rheological characterization of resin-based pit and fissure sealants compared to flowable resin composites. Dent Mater 2012; 28(4):349-59.

14. Sanders BJ, Feigal RJ, Avery DR. Selantes de fóssulas e fissuras e restaurações preventivas em resina. In: Dean JÁ, Avery DR, McDonald RE. Odontopediatria para crianças e adolescentes. 9. ed. Rio de Janeiro: Elsevier; 2011. p. 309-317.

15. Hesse D, Bonifácio CC, Mendes FM, Braga MM, Imparato JCP, Raggio DP. Sealing versus partial caries removal in primary molars: a randomized clinical trial. Oral Health 2014; $14: 58$

16. Pitts NB. Are we ready to move from operative to non-operative/preventive treatment of dental caries in clinical practice? Caries Res 2004; 38(3):294-304.

17. Adewakun AA, Percival TM, Barclay SR, Amaechi BT. Caries status of children in eastern Trinidad, West Indies. Oral Health Prev Dent 2005; 3(4):249-61.

18. Baelum V, Machiulskiene V, Nyvad B, Richards A, Vaeth M. Application of survival analysis to carious lesion transitions in intervention trials. Community Dent Oral Epidemiol 2003; 31(4):252-60.

19. Ripa LW. Occlusal sealants: rationable and review of clinical trial. Clin Prev Dent 1982; 4(2):3-10.

20. Kidd EA. How "clean" must a cavity be before restoration? Caries Res 2004; 38(3):305-13.

21. Ferreira JMS, Pinheiro SL, Sampaio FC, Menezes VA. Use of glass ionomer cement containing antibiotics to seal off infected dentin: a randomized clinical trial. Braz Dent J 2013; 24(1):68-73.
22. Ricketts DN, Kidd EA, Innes N, Clarkson J. Complete or ultraconservative removal of decayed tissue in unfilled teeth. Cochrane Database Syst Ver 2008; (04):1-18.

23. Vasconcelos AA, Girão DC, Parisotto TM, Imparato JCP. Selamento de lesões de cáries oclusais em metade externa de dentina em dentes decíduos: estudo clínico randomizado em crianças cearenses. Odontol Bras Central 2017; 26(77):26-32.

24. Jensen OE, Handelman SL. Effect of an autopolymerizing sealant on viability of microflora in occlusal dental caries. Scand J Dent Res 1980; 88(5):382-8.

25. Borges BC, Campos GB, da Silveira AD, de Lima KC, Pinheiro IV. Efficacy of a pit and fissure sealant in arresting dentin non-cavity caries: a 1-year follow-up, randomized, single-lind, controlled clinical trial. Am J Dent 2010; 23(6):311-6.

26. Oliveira EF, Carminatti G, Fontanella V, Maltz M. The monitoring of deep caries lesions after incomplete dentine caries removal: results after 14-18 months. Clin Oral Investig 2006; 10(2):134-9.

27. Alves LS, Fontanella V, Damo AC, Ferreira OE, Maltz M. Qualitative and quantitative radiographic assessment of sealed carious dentin: a 10-year prospective study. Oral Surg Oral Med Oral Pathol Oral Radiol Endod 2010; 109(1): $135-41$.

Endereço para correspondência:

Yohana de Oliveira Ponte

Rua Padre Valdevino, 1415

CEP 60135-040, Fortaleza, Ceará, Brasil

Telefone: 5585988140131

E-mail: yohanaponte@bol.com.br

Recebido: 22/09/17. Aceito: 07/11/17. 